\title{
A plea for more education for sustainable development
}

\author{
Akito Arima \\ Received: 26 January 2009/Published online: 31 March 2009 \\ (C) Integrated Research System for Sustainability Science and Springer 2009
}

\section{Sustainable development and academia}

In April 1989, I became president of the University of Tokyo and served in that capacity for 4 years. During my tenure, I argued that universities must be centers of scholarship that contribute to the sum total of human wisdom on a level that transcends disciplinary distinctions, such as between science and the humanities. Toward that end, I fought for increases in research spending and improvements to the research and education facilities at Japan's universities, which were in poor condition at the time. In 1995, the Japanese government implemented the Basic Law on Science and Technology and followed up in 1996 with the Science and Technology Basic Plan. This plan, which is revised every 5 years, has helped spur a dramatic increase in competitive funding and other outlays for science and technology research.

Even so, research and education in Japan still face many problems. First of all, funding for the humanities and social sciences is far too meager. If we are to contribute to the advancement of humanity, we must encourage the balanced development of both the hard sciences and the humanities, for which the latter area in particular requires more investment. Second, funding remains woefully insufficient for education on all levels-primary, secondary, and higher. From the standpoint of long-term policy for our

\footnotetext{
A. Arima $(\bowtie)$

Japan Science Foundation/Science Museum,

2-1 Kitanomaru-koen, Chiyoda-ku,

Tokyo 102-0091, Japan

e-mail: arima@jsf.or.jp

A. Arima

Musashi Gakuen, 1-26-1 Toyotama-kami, Nerima-ku,

Tokyo 176-8533, Japan
}

nation, substantive improvement in this area should be a major priority for Japan.

The University of Tokyo, like other universities, has recently seen criticism aimed at the 'reductionist' fragmentation of academic disciplines, with many voices calling for a merging of the sciences and humanities. While I strongly advocate balanced development in both areas, I personally consider it impossible for any one individual to master the entire spectrum of knowledge. Therefore, I think it is unrealistic to expect all students and researchers to gain a comprehensive knowledge of both the sciences and humanities. What I do hope is that scholars in either area will acquire a certain degree of familiarity with the other. At universities, this can be achieved by requiring a minor as well as a major of students.

For this same reason, is it not unrealistic to envision a generation of sustainable development 'specialists' whose perspective simultaneously encompasses the entire field? What research for sustainable development demands is, if anything, increasingly specialized work by experts in such fields as energy, food, and water; however, they must also be capable of collaborating in the overall effort to solve global environmental problems. What is important here is that the specialists in these diverse fields expand their perspective beyond their particular area of expertise enough to create a cooperative framework for combating these global environmental problems together.

To pick one example, the energy field alone requires specialists in thermal power, nuclear power, new energy sources, energy conservation, carbon capture and storage (CCS), and so on. It also needs experts with an interest in the mixing of energy sources, as well as social scientists to aid in such tasks as the diplomatic negotiations required to achieve a balance of national interests in the resolution of global energy issues. We need to establish venues where 
these specialists can broaden their perspectives by meeting together and discussing the larger picture. Then, as the Intergovernmental Panel on Climate Change (IPCC) has attempted to do, we need to ensure that the results of these discussions are reflected in solution-oriented public policy. This is a formidable but unavoidable task for academia if it is to contribute to sustainable development.

\section{Why we need education for sustainable development}

I have been engaged with these issues since 2003, around the time the United Nations Educational, Scientific and Cultural Organization (UNESCO) launched its initiative on Education for Sustainable Development (ESD), and am a member of the High-Level Panel on the United Nations Decade of Education for Sustainable Development (UNDESD, 2005-2014). Initially, I thought that ESD efforts should focus on education in the United States and other industrialized countries, which are the primary origin of global environment problems, and that it was less necessary to involve developing nations in Africa and elsewhere. Now, however, I think that this was an erroneous assumption.

The industrialized nations must certainly strive to conserve resources and energy. However, it is now feared that the rapidly rising consumption of resources and energy accompanying the growth of the developing nations, particularly emerging economies like China and India, is a serious threat to global sustainability as well. Consequently, a key to sustainable development is the ability of these developing nations to pursue growth that conserves energy and resources without repeating and exacerbating the errors already committed by the developed nations.

The developed and developing countries must join forces in creating the resource- and energy-conserving technology needed for this purpose, and this is where education for sustainable development plays a crucial role. Over the past few decades, Japan has succeeded in dramatically reducing its own previously severe pollution levels, and our country has a history of pursuing resource and energy conservation. The results can be seen in Japan's low level of carbon dioxide emissions relative to gross domestic product (GDP) (Figs. 1 and 2). Another critical task of ESD is, therefore, the training of professionals who can transmit the experiences of the industrialized nations to developing and emerging nations and use it there to promote sustainable development, taking as an object lesson the mistakes made by the industrialized nations.

The educational process itself has tremendous bearing on the success of such efforts. For many years, I have argued that education need impart only a minimal amount of knowledge per se; what is important is that students

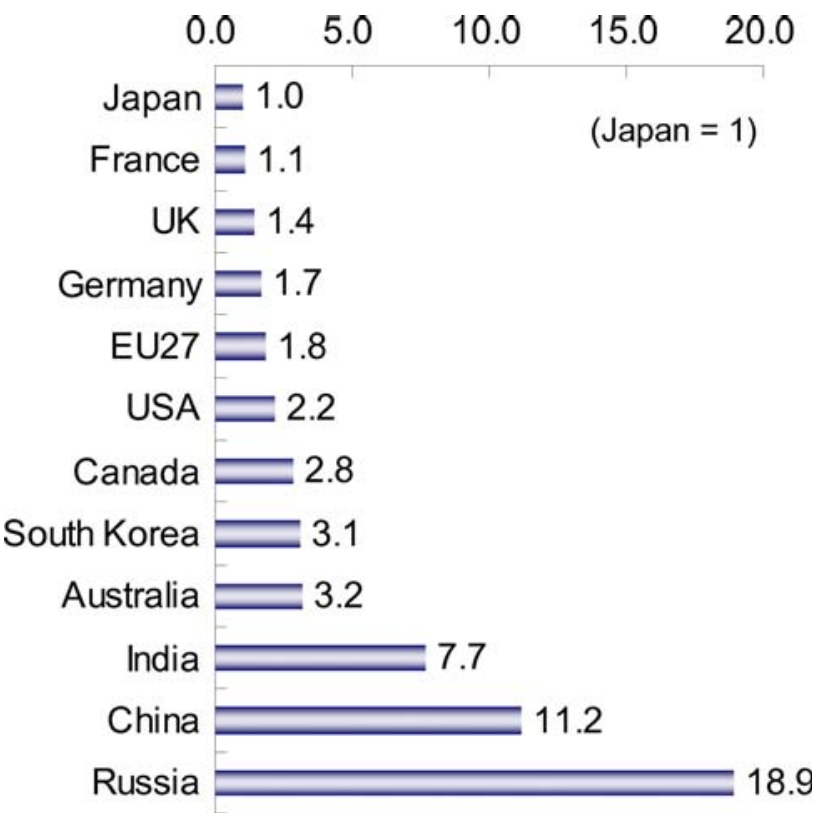

Fig. 1 Carbon dioxide $\left(\mathrm{CO}_{2}\right)$ emissions per gross domestic product (GDP) (2004). $\mathrm{CO}_{2}$ emissions per GDP (1,000 USD) with Japan's unit consumption used as the base number of 1.0. Source: IEA Energy Balances of OECD Countries 2003-2004

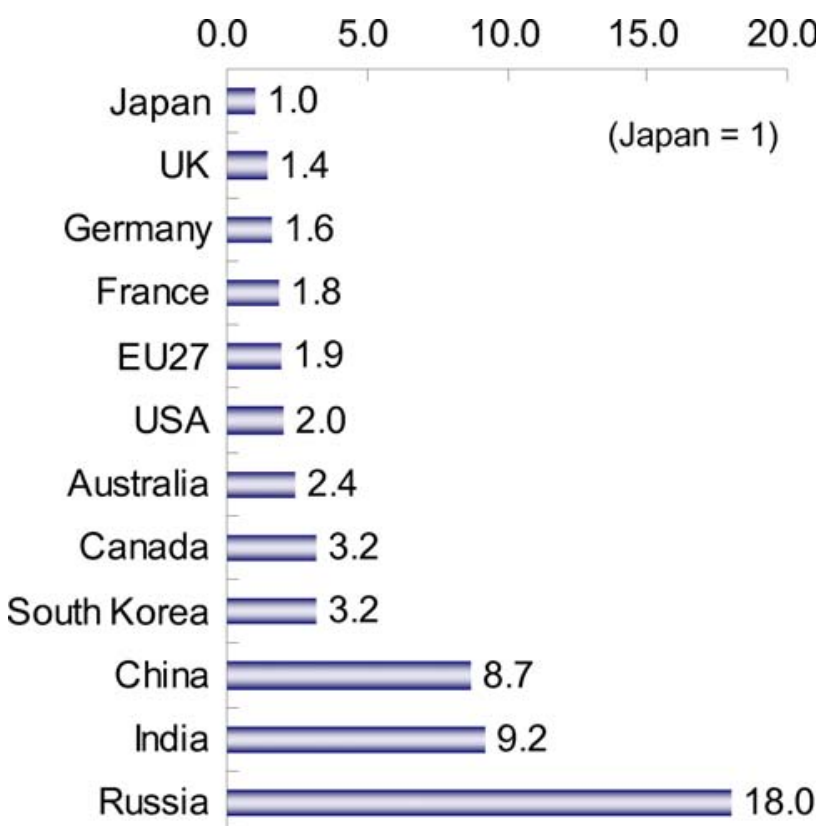

Fig. 2 Primary energy consumption per GDP (2004). Primary energy consumption (oil equivalent ton) per GDP (1,000 USD) with Japan's unit consumption used as the base number of 1.0. Source: IEA Energy Balances of OECD Countries 2003-2004

acquire the ability to solve problems and improve themselves. This is essential in developed and developing nations alike. In the most impoverished countries, affording children enough time for education is itself a problem, but even in such circumstances, children must be 
inculcated with the knowledge they need for their survival. Is this not, after all, the fundamental philosophy behind the UN's Education for All initiative?

Even in developed countries, education, particularly at the primary and secondary levels, must imbue young people with the strength and skills to survive. But it must also foster in them the capacity to empathize with the lives of people in other, poorer countries. This requires educational programs that provide children in developed countries the opportunity to experience the rigors of life without possessions. At the higher education level, volunteer work in developing countries should be encouraged. In this respect, I am much impressed by the activities in places like Asia and Africa of the Japan Overseas Cooperation Volunteers (JOCV). Efforts by such organizations demand our active support.

\section{Specific steps toward sustainable development}

My experience with ESD in the Asia-Pacific region has taught me that we cannot simply introduce programs like Japan's Mottainai (Do not Waste) or 3R (Reduce, Reuse, Recycle) campaigns to the most impoverished nations of Asia or Africa and expect them to work. International cooperation that helps these countries develop on their own is the best vehicle for assisting them. That, I believe, is the path to sustainable development.

Sustainable development, above all, is a challenge to our approach to development. It does not reject development out of hand, but demands a new form of it that utilizes local resources as efficiently as possible while minimizing the impact of development on the environment. This means that sustainable development could, in fact, be key to surmounting the 'North-South' problem. The fundamental task of education for sustainable development is, therefore, to contemplate how to maintain global sustainability while continuing development, which is, after all, the basis for human survival.

The concept of sustainable development does not, I believe, start and end with economic development. 'Development' here must include the development of science and technology, as well as of society. Scientific and technological advances, in particular, are essential to the achievement of global sustainability in such areas as resource and energy conservation, developing new energy sources, increasing the food supply, and resolving water issues. Progress in science and technology will naturally lead to economic progress, and the advent of 'eco-economics' will, in turn, open the path to a sustainable society.

A variety of alarms are sounding today over problems involving energy and resources (including food and water) and the global environment, notably climate change. The underlying message of all these warnings, however, is the same: now is the time for humanity to mobilize the sum total of its wisdom and knowledge, including the natural sciences, the humanities, and the social sciences. I am optimistic enough to believe that, if advances in science and technology that help us conserve resources and energy, and develop new energy sources, are accompanied by the application of the wisdom of the humanities and social sciences so as to impel changes in human lifestyles and social structures, we will surely achieve a sustainable society.

'Sustainable development,' composed of two words that once seemed mutually incompatible, is, in fact, an extremely profound concept. In that sense, too, it should not be construed as applying only to economic development. Acknowledging that humanity cannot return to the way it lived before the Industrial Revolution, I firmly believe that sustainable development is what will guide us on a path of advancement based on the constructive use of science and technology to preserve resources and the environment. This positive outlook is, indeed, a crucial aspect of what ESD should be imparting to the next generation.

Human wisdom is limitless in its potential. My fervent hope is that this wisdom will, henceforth, be used to the fullest extent possible to lead humanity in the direction of peaceful development, rather than toward the destruction of our collective welfare. Science and technology must also evolve in a direction conducive to sustainability. In the sense that we are privileged to respond to this new challenge, the era we live in is truly a marvelous and fascinating time. It is, above all, a time for pooling the full aggregate of human wisdom, that we may pass it on to the next generation. 